The oblate and prolate shells were each of them made from the two hemispheres of sheet copper which plumbers solder together to make their globular floaters. By a littie hammering it is easy to alter the hemispheres to the proper shapes to make either the prolate or the oblate figure.

Theory had pointed out that the rotation of a liquid in a rigid shell of oval figure, being a configuration of maximum energy for given vorticity, would be unstable if the containing vessel is left to itself supported on imperfectly elastic supports, although it would be stable if the vessel were held absolutely fixed, or borne by perfectly elastic supports, or left to itself in space unacted on

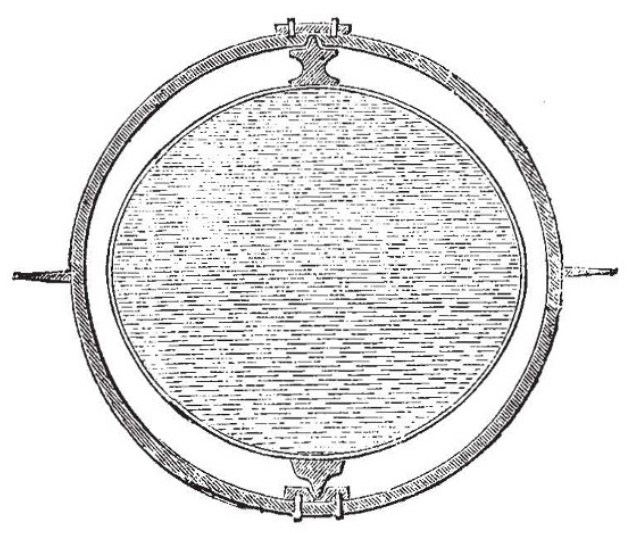

by external force; and it was to illustrate this theory that the cyal shell was made and filled with water and placed in the apparatus. The result of the first trial was literally startling, although it ought not to have been so, as it was merely a realisatien of what had been anticipated by theory. The framework was held as firmly as possible by one person with his two hands, keeping it as steady as he could. The spinning by means of a fine cord ${ }^{1}$ round a small $\mathrm{V}$ pulley of $\frac{1}{3}$-inch diameter on the axis of the oval shell, and passing round a large fly-wheel of 3 feet diameter turned at the rate of about one round per sicond, was continued for several minutes. This in the case of the oblate shell, as was known from previous experiments, would have given amply sufficient rotation to the contained water to cause the apparatus to act with great firmness like a solid gyrostat. In the first experiment with the oval shell the shell was seen to be rotating with great velocity during the last minute of the spinning; but the moment it was released from the cord, and when, ho!ding the framework in my hands, I commenced carrying it towards the horizontal glass table to test its gyrostatic quality, the framework which I he'd in my hands gave a violent niacontrollable lurch, and in a few seconds the shell stopped turning. I saw that one of the pivots had become bent over, by yielding of the copper shell in the neighbourhood of the stiff pivot-carrying disk, soldered to it, showing that the liquid had exerted a very strong couple against its containing shell, in a plane through the axis, the effort to resist which by my hands had bent the pivot. The shell was refitted with more strongly attached pivots, and the experiment has been repeated several times. In every case a decided uneasiness of the framework is perceived by the person holding it in his hands during the suning; and as soon as the cord is cut and the person holding it carries it towards the experimental table, the framework bagins, as it were, to wriggle round in his hands, and by the time the framework is placed on the table the rotation is nearly all gone. Its utter failure as a gyrostat is precisely what was expected from the theory, and presents a truly wonderful contrast from what is obierved with the apparatus and operations in every respect similar, except having an oblate instead of a prolate shell to contain the liquid.

I Instead of using a long cord first w. und on a bobbin, and finally wound up in the circumference of the large wheel as described in NATURE, February $x, 1877$, p. 297 , I have since found it much more convenient to use an endless cord little more than half round the crrcumference of the large wheel, and less than half round the circumference of the $V$ pulley of the gyrustat: and $t$, keep it tight enough to exert whatever tangential torce on the $\mathrm{V}$ pulley is desired by the ferson holding the framework in his hand. After continuing the spinning by turning the fly-wheel for as long a time as is judged proper, the endless cyrd is cut with a pair of sciscors and the gyrostat released.

\section{ON A DISTURBING INFINITY IN LORD RAYLEIGH'S SOLUTION FOR WAVES IN A PLANE VORTEX STRATUM}

IN the paper in last week's NATURE under this heading by Sir William Thomson, the lower part of the illustration was inadvertently turned round at the last moment by the printer ; the cut should stand as follows :-
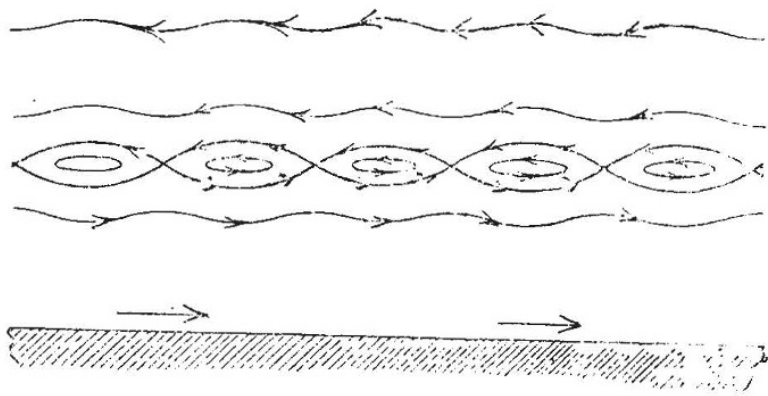

\section{SARGASSL:M 1}

THIS paper opens with a discuscion of the value of the species Sargassum bacciferum, the particular species of this genus which is well known as the Gulf-weed. The author considers that the floating plants to which this namej has been given are simply fragments of many varieties or species of Sargassum, more particularly of $S$. vulgare. In support of this; view he points out that, from the accounts of nearly all authors who have examined specimens, it appears that the lower part of the stem had been broken across, and that it is therefore fair to conclude that they belong to plants which are rooted under ordinary circumstances. This conclusion had been already arrived at by Rumphius, C. Agardh, Rennell, Humboldt, and more recently by G. von Martens; but of the e writers Iiennell and Humboldt are of opinion that the floating fragments continue to grow, and in this they agree with Thunberg, Meyen, and Harvey. Dr. Kuntze contends that there is not sufficient evidence forthcoming to establish the correctness of this view. He urge; that, even admitting that some growth takes place, it is only temporary, and that it therefore affords no ground for regarding these as pelagic plants. The only other cases of growth of Fuci when floating are offered by Macrocystis pyrifera (Sir Joseph (Mr. Moseley, "Notes by a Naturalist ond by Fucus vesiculosus doubtless Dr. "Notes by a Naturalist on the Challenger"), and question naturally arises as to whether these floating plants are actively living, or are dying, or dead.

In the case of Sargassum Dr. Kur tze considers that their bright yellow colour is due to changes taking place, either preliminary to or in consequence of deatb, in the brown colouring-mat:er of the attached forms to which he believes the floating fragments belong. Mr. Moseley, however, is of opinion that this is the natural colour of these plants whilst living. It does not appear that any such difference in colour has been noticed in attached and floating specimens of Macrocystis or of Fucus, and this is a fact which is not in harmony with Dr. Kuntze's views respecting Sargassum. Again, the general ob:ervation that these floating Fuci have no reproductive nrgans offers a further difficulty which they do not explain. Dr. Kuntze endeavours to meet the diffi. culty by stating that he has found receptacles occasionally in free-swimming individuals, and he gives figures of two plants bearing them; but neither from the fizures nor from his account of them is it possible to conclude with certainty that the bodie: in question are really of a repruductive nature; and he explains the usual absence of the e organs in the floating individuals by suggesting that the receptacles, being the most fragile parts of the plant, are the most readily destroyed, and further that, owing to the small number of air-chambers with which they are provided, they would sink on becoming detached. In this case, as in that of the colour, these explanations respecting Sargassum will only become valid when they are found to hold good of Macrocystis and of Fucus also. It is apparent that the

$x$ "Revision von Sargas-um und das sogenannte Sargasso-Meer." Von Dr. Otto Kuntze (Engler's botanische faibrbïcher, Bd. i. Heft iii., I $8 \&$ ). Leipzig, Engelmarn.) 
evidence offered in support of Dr. Kuntze's views is at present incomplete, and that further researches into the life-history of these plants must he made before these views can be generally accepted.

After an elaborate systematic revision of the genus, $\mathrm{Dr}$. Kuntze goes on to discuss the Sargas:o Sea. He draws attention to the wide divergences which exist between the accounts given of it by different travellers. Thus Humboldt and Maury speak of it as a mass of gulf-weed having an area of thousands of square miles, whereas others-Sir Wyville Thomson, for instance-describe it as consisting of small scattered patches. Dr. Kuntze concludes that there is no reason for assigning a definite and constant area to it. It appears that the patches of weed occur more frequently in the region of calms, but at times it is either absent or present only in small quantities even there. A wind blowing for a considerable time in one direction might, under certain circumstances, cause the aggregation of patches into a mass of some extent, such as is to be found, for instance, in the neighbourhood of the Bermudas in spring after the cquinoctial gales, but even this would be but small when c mpared with Humboldt's estimate.

\section{UNIVERSITY AND EDUCATIONAL INTELLIGENCE}

OXFORD. - The following gentlemen have been nominated by the Vice-Chancellor as examiners for the Degree of Bacbelor of Medicine. In the first examination for M.B. :-S. H. West, M A., M.B. Christ Church; J. A. Dale, M.A. Balliol; A. G. Vernon Harcourt, M.A. Christ Church. In the second examination for M.B.:-T. K. Chambers, M.D., Christ Church; James Andrews, M.D., Wadham; T. P. Teale, M.A., M.B., Brasenose. In the examination in Preventive Medicine :-W. Ogle, M.D. Corpus; G. W. Child, M.D. Exeter; W. F. Donkin, M.A. Magdalen; Douglas Galton, Capt. R.E., Hon. D.C.L.

A Fellowship will shortly be offered by University College for proficiency in biology. The details are not yet announced.

\section{SCIENTIFIC SERIALS}

Anvalin der Physits und Chenie, No. 10.-On the influence of curvature of the wall on the constants of capillarity in wetting liquids, by P. Volkmann. - Constructions for anomalous dispersion, by E. Ketteler.-On Newton's dust-rings (continued), by K. Exner.-On calculation of the correction for temperature in calorimetric measurements, by L. Pfundler.--Chemical energy and electromotive force of various galvanic combinations, by J. Thomsen. - On the photo- and thermo-electric properties of fluor spar, by W. Hankel.-On electrical elementary laws, by E. Riecke.-Remarks on some recent electro-capillary experiments, by E. Lippmann.-Experimental researches on weakly magnetic substances (third part), by $\mathrm{P}$. Silow. - Researches on the height of the atmosphere and the constitution of gaseous heavenly bodies (continued), by A. Ritter.-Reply to Herr Herwig "On the Heat-Conductivity of Mercury," by II. F. Weber--Reply to IIerr Winckelmann's remarks in a recent number, by the same.

Archives des Siences Phy'siques et Naturelles, October 15.Contributions to a study of the colouring-matters of plants, by J. B. Schnetzler. - Practical study of marine zoology; the zooJogical station of Naples, by E. Yung.-Sixty-third session of the Helvetic Society of Natural Sciences, held at Brigue on September 13-15, I880; Proceedings in the departments of Physics and Chemistry, Geology, Botany, Zoslogy and Medicine.

\section{SOCIETIES AND ACADEMIES \\ LONDON}

Linnean Society, November 4--Prof. Allman, F.R.S., president, in the chair. - The session opened by Mr. H. C. Sorby showing drawings of some British sea-anemones, with habitat on the upper fronds of long seaweeds in deep water; and he recorded having seen a solitary cream-coloured cetacean on the English coast.-Mr: Arthur Bennett drew attention to a new British Chara ( $C$. stelligera), remarkable for the presence of stellate bulbils on the stems. -Mr. E. M. Holmes exhibited two marine algæ new to Britain, viz., Dasya sibbesii, from Berwickon-Tweed, and Ectocarpus terminalis from Weymouth; and also species of Callithamnion, with antheridia and trichophore on the s.me branchlet.-Prof. T. S. Cobbold exhibited a remarkable trematode from the horse. It was dircovered by Dr. Sonsini at
Zagazig during the Egyptian plague, with which outbreak, however, the parasite had no necessary connection. The worm (Gastrodiscus sonsinonis) appeared to be an aberrant amphistome furnished with a singular ventral disk, whose concavity was lined with about 200 small suckers having a tesselated aspect. In this respect its nearest approach was a worm infesting a genus of spinny-finned fishes (Cataphractus) belonging to the Triglidx. According to Prof. Leuckart's recent anatomical investigation, however, doubts are thrown on its amphistomoid affinities, $-\mathrm{Mr}$. G. F. Angas showed the leaf of Hermas gigantea, an umbelliferous plant of the Cape used as tinder by the Hottentots.-Mr. E. A. Webb exhlibited a monstrous bramble (Rubus fruticosus) with flowers represented by elongated axes covered with minute pubescent bract; $;$ and apices fasciated. - A communication by Dr. G. Watt was read, viz., contribution to the flora of NorthWest India. The geographical features of the district are noted. He divides it into three areas : the first range, Ravee-Basin, with magnificent forests of Cedrus dtodara on its northern slopes, has on the southerly ones vegetation with an Indian facies, being barely outside the humid influence of the tropical rains of the plains; the second range, comprising Pangi, Lower Lahore, and British Lahore, has a flora altogether changed, dry short summers and snow-clad mountains giving a climate and plantlife of quite a different cast ; the third range evinces still further change of flora, this assuming a Thibetan type. Some 300 species of plants are noted, four being new.--A paper on the Papilionidx of South Auctralia, by $\mathrm{J}^{\top} \mathrm{G}$. Otto Tepper, was read. The butterflies of this part of Austral $z$ are comparatively few in numbers, and sombre colours prevail thus seemingly in harmony with the surroundings of their habitat. The paucity of numbers the author attributes to the dryness of the climate. Notes on the habits accompany the descriptions of the species.-Note; on a collection of flowering plants from Madagascar were read by $\mathrm{Mr}$. J. Cr. Baker. The flowering plants are less lnown than the fern; from this interesting island; two new genera are denoted, viz. (I) Kitchingia, belonging to the Crassulacex, a succulent herb with fleshy sessile leaves and large bright red flowers in lax terminal cymes; (2) Rodocodon, a liliaceous plant with red flowers and peculiar spurred bracts : it comes between Muscaria and Urginea. Thirty new species are described.-Messrs. Edw. Brown, II. E. Dresser, and T. F. Pippe were elected Fellows of the Society.

Mathematical Society, November I I.-Mr. C. W. Merrifie!d, F.R.S., president, in the chair.-The Treasurer's and Secretaries' reports were read and adopted. - After the ballot had been taken, the gentlemen whose names are given on p. 614 of the last volume were declared duly elected as the Council for the present session. -Mr. S. Roberts, F.R.S., the new president, having taken the chair, Mr. Merrifield read his valedictory address, "Considerations respecting the Translation of Series of Observations into Continuous Formulx."-On the motion of Prof. Cayley, F.R.S., the address was ordered to be printed in the Procecdings. - $\mathrm{Mr}$. H. M. Jeffery, F.R.S., then read a paper on bicircular quartics, with a triple and double focus, and three single foci, all of them collinear.-Mr. Tucker (hon. sec.) communicated parts of a paper by the Kev. C. Taylor, further remarks on the geometrical method of reversion.

Geological Society, November 3.-Robert Etheridge, F.R.S., president, in the chair.-Bernard Barham IVoodwari was elected a Fellow of the Society.-The President announced that the original portrait of Dr. William Smith, painted by M. Fourau in the year 1838 , had been presented to the Society by Mr. William Smith of Cheltenham.-The following communications were read:- On the serpentine and associated rocks of Anglesey, with a note on the so-called Serpentine of Porthdinlleyn (Caernarvonshire), by Prof. T. G. Bonney, F.R.S., Sec. G.S. Several patches of serpentine are indicated on the Geological Survey map on the western side of Anglesey, near Tre Valley Station, and a considerable one on Holyhead Island, near Rhoscolyn. These really include three very distinct varie. ties of rocks: (I) compact green schistose rocks, (2) gabbro, (3) true serpentine. The anthor described the mode of occurrence of each of these, and their relations, the serpentine being almost certainly intrusive in the schist, and the gabbro in the serpentine. The microscopic structure of the various rocks was described in detail, especially of the last. It presents the usual characteristics, and is an altered olivine rock which has contained bronzite. One or two varieties are rather peculiar; an ophicalcite and a compact chloritic $\mathrm{s}$ hist containing chromite are also noticed. 